Article

\title{
How Corporations Deal with Reporting Sustainability: Assessment Using the Multicriteria Logistic Biplot Approach
}

\section{Purificación Vicente Galindo ${ }^{1}$, Eric Vaz ${ }^{2, *}$ and Teresa de Noronha ${ }^{3}$}

1 Department of Statistics, University of Salamanca, Campus Miguel Unamuno, Universidad de Salamanca, 37007, Salamanca, Spain; E-Mail: purivic@yahoo.com

2 Department of Geography, Ryerson University, 350 Victoria Street, Toronto, ON M5B 0A1, Canada

3 Faculty of Economics, and CIEO, University of the Algarve, 8000, Faro, Portugal; E-Mail: mtvaz@ualg.pt

* Author to whom correspondence should be addressed; E-Mail: evaz@ryerson.ca; Tel.: +1-416-979-5000 (ext. 3121); Fax: +1-416-979-5000.

Academic Editors: Graham Winch and Carmine Bianchi

Received: 4 November 2014 / Accepted: 21 January 2015 / Published: 27 January 2015

\begin{abstract}
This paper suggests a new methodology capable of accessing in detail the contribution of companies to countries' sustainability related to economic performance. The concept of sustainability has been brought up in several debates, leading to a clearer understanding of its progress in recent decades. The most adequate indicators to achieve a unique value to define sustainability have been identified. However, specific behaviors of economic agents such as exist in particularly large organizations, have rarely been exposed and evaluated regarding their positive or negative contribution to the increase of sustainability throughout the world. This paper proposes an integrated approach incorporating an evaluation of the positive and negative contributions to sustainability by means of a logistic biplot application. This allows the creation of a summarized index that combines all single sustainability indicators. These synthetic indices allow the positioning of each of the companies in a geometric representation for an original exploration of the sustainability paradigm. The supplied method permits accessing and evaluating information concerning specific behaviors of economic agents such as big companies. In our paper, we have followed the engagements towards sustainability of big corporations, individually or as groups, across the different activity sectors in Portugal and Spain.
\end{abstract}


Keywords: Logistic Biplot; Global Reporting Initiative (GRI); sustainability; large corporations; social responsibility

\section{Introduction}

This paper proposes a new methodology capable of accessing in detail how companies are contributing to a country's sustainability. The concept of sustainability has been submitted to long debates and its understanding has progressed significantly in recent decades. While the key variables that structure sustainability have been defined, the analytics of economic agents within large corporations have rarely been discussed or evaluated related to sustainability. Their positive or negative contributions to the increase of sustainability throughout the world should therefore be clearly understood within the context of our sustainable futures [1].

Today's collapsing global economic system is extremely dependent on large corporations. This is the case both from a production as well as a consumption structure. The integrative role of production and consumption makes it particularly important to have a holistic assessment analysis of how such actors interpret and assume their social responsibility. Ghisetti and Quatraro [2] enhance this debate by stressing the incentives of environmental innovations. Furthermore, the role of large corporations as decision makers directly influences national governance structures, leading to a direct application within their socio-ecological environments. This supports framing more adequate and updated regulations, which may have impacts on better corporation performance, as well as more sustainable choices. This paper assesses the efforts of such corporations towards sustainability, profiled as individuals or groups, across the different sectors in Portugal and Spain.

During the last three decades of its integration in the European Union, Portugal and Spain have benefited from a significant amount of financial support for a dynamic promotion of their industrialization as well as service sectors. It is well known that new investments have focused mainly on accessibilities, training, and creation of new industries and services. As such, several big companies have changed to innovative products either related to new information and communication technologies or renewable energies. Particularly in Portugal, green energy has been rendered as a strategic goal. The significant energetic dependency in the past, as well as the historical use of hydraulic resources, were two major drivers to commit to optimizing energy in Portugal. As a result of this, Portuguese composition of composition of the energy consumption patterns changed considerably in less than a decade.

A twofold goal is adopted in this research: On one hand, we aim to bring big companies into the discussion of sustainability claiming their social responsibility and peruse with adequate indicators their indicators their sustainable behaviors. On the other hand, this paper aims to provide an integrated model, as well as a pragmatic methodology that perceives the relative position of each company in the overall, national or international picture regarding their role within sustainability. This can be accomplished by using the set of approaches towards sustainability of each corporation. We believe that by investigating the performance of large companies, as regards their approaches towards sustainability, a significant progress for public as well as political attention is provided. This deems to be a fundamental characteristic for the social responsibility that these companies hold for a sustainable 
future. The reliance of the global productive system on an array of small and medium enterprises, leads to a significant component of private participation which is generally not considered. However, on a global scale, most of the production is reduced to large scale methods and equipment, as well as increasingly to agglomeration economies, leading to the great compensations of large corporations.

The difference between social and sustainability responsibility can be understood by the active engagement and interaction on the short and medium run. Social responsibility affects the short run of societal responsibility, while the latter focuses on long term commitments towards global goals that should be long lasting. In this sense, sustainability is a multidimensional concept that does not necessarily include the ecological dimension, but expands on the complexity of a social, as well as economic and institutional framework ([3]). Sustainability is, as such, a process of optimization that does not only have repercussions on a unique optimal solution, but rather, a ubiquitous application, enclosed by domains of unsustainable behaviors in which regulation plays an important role. Sustainability is also dynamic [4] and performs reproductive cycles. These cycles evolve not only because they are conterminous with the material flows within the throughputs such as energy and other resources, but are also due to the change of values by actors [5] or adaptive management [6]. Moreover, actors do interfere in such reproductive cycles either by actions at the macroeconomic level, following political decisions and national regulations generally, or by different microeconomic behaviors at the household, community or company level.

The first challenge we had to face consisted of acquiring reliable sustainability indicators, given the extensive amount of different available indicators. Furthermore, Marimon and others [7] have provided substantial information on the different standards available for such studies, each one with their own criteria. When comparing those with the United Nations Global Compact Principles, the OECD Directory for Multinational Enterprises, the Global Reporting Initiative (GRI), the ISO 26000 and others, the GRI showed a stronger conciliation registering economic, environmental and social issues. The GRI, having been created in 1997, holds a unique importance pertaining to its broadly known voluntary guidelines for corporate sustainable reporting, envisioning to promote new strategies for corporations.

As pointed out by Perez-Batres and others [8] companies that have adopted the GRI lined up their strategies by addressing key issues such as human rights, labor, environment, and practices of anti-corruption.

This paper adopts an analytical perspective of the pathways of sustainability reporting by such corporations, and adheres to the following structure: Following by the Introduction, which supplies a framework for the models and measures of sustainability, a section of Material and Methods addresses the reliability of the data used. Further, this section explores the reasons why Portuguese and Spanish companies are of importance in such an analysis, and reports on robust statistical methods in its understanding. The Analyses and the Discussion of Results are the two next sections, offering the most innovative part of the paper. Finally, the Conclusion summarizes the main general findings of this research.

\section{Material and Methods}

\subsection{Reliable Secondary Data Bases: The GRI Reports}

The Coalition for Environmentally Responsible Economies (CERES) was founded in 1997 based on a joint program within the United Nations Environment Programme. This program had the objective of 
offering a more rigorous and useful reporting system for sustainable development. As a non-profit organization promoting economic, environmental and social sustainability, it offered a more integrated vision for sustainable development, comprising the importance or sustainability within large organizations. In 1998, under the framework of the GRI, a pivotal mandate of the Steering Committee, was to "do more for the environment." On this advice, the framework's scope was broadened to include social, economic, and governance issues. GRI's guidance became a Sustainability Reporting Framework, addressing reporting guidelines. The first official edition of the GRI regulations were introduced in June 2000, within the program of the United Nations Environment Programme (UNEP). The proposal was based on expanding globally the financial reporting system of the United States (FASBI) with some improvements, such as intensifying the content and extent of environmental indicators and the inclusion of stakeholders in the process of creation [9]. In 2002, the second version of the regulations was proposed, where corporate sustainability criteria are standardized and Performance Indicators were organized in economic, environmental and social categories. The result of this structure in three blocks, is called the triple bottom line (TBL) reporting system or "People, Planet, Profit" [10]. Nowadays, is mostly used in the preparation of guides for sustainability reporting

In this paper, addresses the reports G3.1 and G3 Guidelines corresponding to the third generation of the Global Reporting Initiative (GRI). This envisions a sustainable global economy which combines long-term profitability with social justice and environmental care. From a sustainability perspective, this abridges key dimensions of economic, environmental, social and policy performance.

The uptake of the GRI's guidance was boosted by the 2006 launch of the current generation of GRI, G3. Over 3,000 experts from across business, community and labor participated in G3's development. In March 2011, the GRI published the G3.1 Guidelines as an update and completion of G3, with expanded guidance on reporting gender, community and human rights-related performance (further information can be found at [11]. G3.1 includes expanded guidance for reporting on Human Rights, local community impacts and gender. G3.1 was launched in March 2011 and is the most comprehensive sustainability reporting guidance available. G3.1's Performance Indicators are organized into three categories: Economics, Environment and Social. The Social category is extended into the following subcategories: labor, human rights, society, and product responsibility. G3.1 is a completed update of the GRI's most recent generation of Sustainability Reporting Guidelines, and corresponds to the most comprehensive sustainability reporting guidelines available. A myriad of organizations, from all sizes as well as sectors, use GRI's Framework as to assess and transfer their sustainability performance. The new generation GRI-G4, published in 2013, eliminates the distinction between core and additional indicators. Furthermore, application levels disappear and return to the binary encoding of the first versions; the reports will be declared as "consistent" or "not consistent" with the limits set by the organization of the GRI. For the moment, very few enterprises have benefited from the G4 Sustainability Reporting.

Finally, we should clarify that a sustainability report is a report published by a company or organization about the economic, environmental and social impacts caused by its everyday activities. Beyond its specific indicators, at the heart of the GRI is a commitment to 11 reporting principles: transparency, inclusiveness, auditability, clarity, completeness, relevance, sustainability context, accuracy, neutrality, comparability, clarity and timeliness (each of these is explained in detailed within the GRI guideline documents; see [12]. These principles help reporters define the report and indicator content, the quality of the report, and give guidance on how to set boundaries of reporting. GRI reports increased (from 
2008 to 2010) a 50\% in Asia, 45\% in Europe, 45\% in Latin America, 42\% in North America, 12\% in Oceania and 8\% in Africa, according to Sustainability Disclosure data Base at August 1, 2013.

\subsection{The Assessment of Portuguese and Spanish Organizations}

In order to conduct this research, all available organizations in both Portugal and Spain with a GRI report in 2011 were selected. The data used in this paper was organized in an ixj binary data matrix (X) in which the I rows correspond to the 216 Spanish and Portuguese companies (178/18) and the $\mathrm{J}$ columns correspond to 35 binary characters (or indexes) referring to the Socio Economic dimension (economic performance EC1, EC3, EC4), (market presence EC6, EC7), (indirect economic impacts EC8), (equal remuneration for women and men LA14), (child labor HR6), (local community SO1), (corruption SO4), (compliance SO8), (local community, SO9, SO10); Environmental dimension (EC2, financial implications due to climate change) (materials EN1, EN2), (energy EN3, EN4), (water EN8), (emissions, effluents and waste EN16, EN17, EN19, EN20, EN21, EN22, EN23); Institutional dimension (products and services EN26, EN27), (compliance, EN28), (training and education LA10), (public policy SO5), (costumer health and safety PR1), (product and service labelling PR3), (marketing communications PR6), (compliance PR9), in 2011.

Additional indicators, such as those indicators identified in the GRI Guidelines that represent emerging practice or address topics that may be material to some organizations but not generally for a majority, were not considered.

All binary variables take the value of 1 when the characteristic is present, and 0 in its absence.

EC2 and EC7, economic indicators, are the least reported. Only 57.9\% of the Spanish companies report EC2 index in 2011 and 60.7\% report the EC7. In Portugal, the percentages are slightly larger. On average, for both countries, EC2 and EC7 are reported in $73.2 \%$ and $72.1 \%$ of reports, respectively. Almost all companies, however, have reported EC1 93.5\%.

The activity sectors selected to undertake this research are those established in the Statistical Classification of Economic Activities in the European classification system [13], NACE is similar in function to the Standard Industrial Classification (SIC) and to the North American Industry Classification System (NAICS).

The first four digits of the code, which are the first four levels of the classification system, are the same in all countries in Europe. The fifth digit might vary from country to country and suppliers of databases sometimes place further digits. A: agriculture, forestry and fishing; B: mining and quarrying; C: manufacturing; D: electricity, gas, steam and air conditioning supply; E: water supply; sewerage, waste management and remediation activities; F: construction; G: wholesale and retail trade. Repair of motor vehicles and motorcycles; $\mathrm{H}$ : transportation and storage; I: accommodation and food service activities; J: information and Communications; K: financial and insurance activities; L: real estate activities; M: professional, scientific and technical activities; $\mathrm{N}$ : administrative and support service activities; O: public administration and defense; compulsory social security; P: education; Q: human health and social work activities; R: arts, entertainment and recreation; S: other services; U: activities; T: activities of households as employers; undifferentiated goods and services, producing activities of households for own use; U: activities of extraterritorial organizations and bodies. 
These sectors were grouped as follows (Tables 1 and 2):

Table 1. Sector IDs.

\begin{tabular}{ll}
\hline Group ID & Sector \\
\hline A and B & NACE classification sections: Primary Sector (PS) \\
C & Industrial Sector (IS) \\
D and E & Water and Energy (WE) \\
F & Construction (CN) \\
G to N & Services Sector (SS) \\
O to Q & Public Administration and Social Services (ASS) \\
P & Education (ED) \\
R, S, T, U and V & Others (OT) \\
\hline
\end{tabular}

Table 2. Sample size of Sectors.

\begin{tabular}{ll}
\hline Sector & Sample Size \\
\hline Primary & $0.5 \%$ \\
Water and Energy & $17.1 \%$ \\
Services & $47.22 \%$ \\
Construction & $6.5 \%$ \\
Public Administration and Services & $6.00 \%$ \\
Education & $2.30 \%$ \\
Industrial & $3.20 \%$ \\
Others & $17.10 \%$ \\
\hline
\end{tabular}

The study considered public (6.00\%) and private organizations (66.0\%), as well as other types (28\%).

The figure below (Figure 1) shows the distribution of companies both in Spain and Portugal.

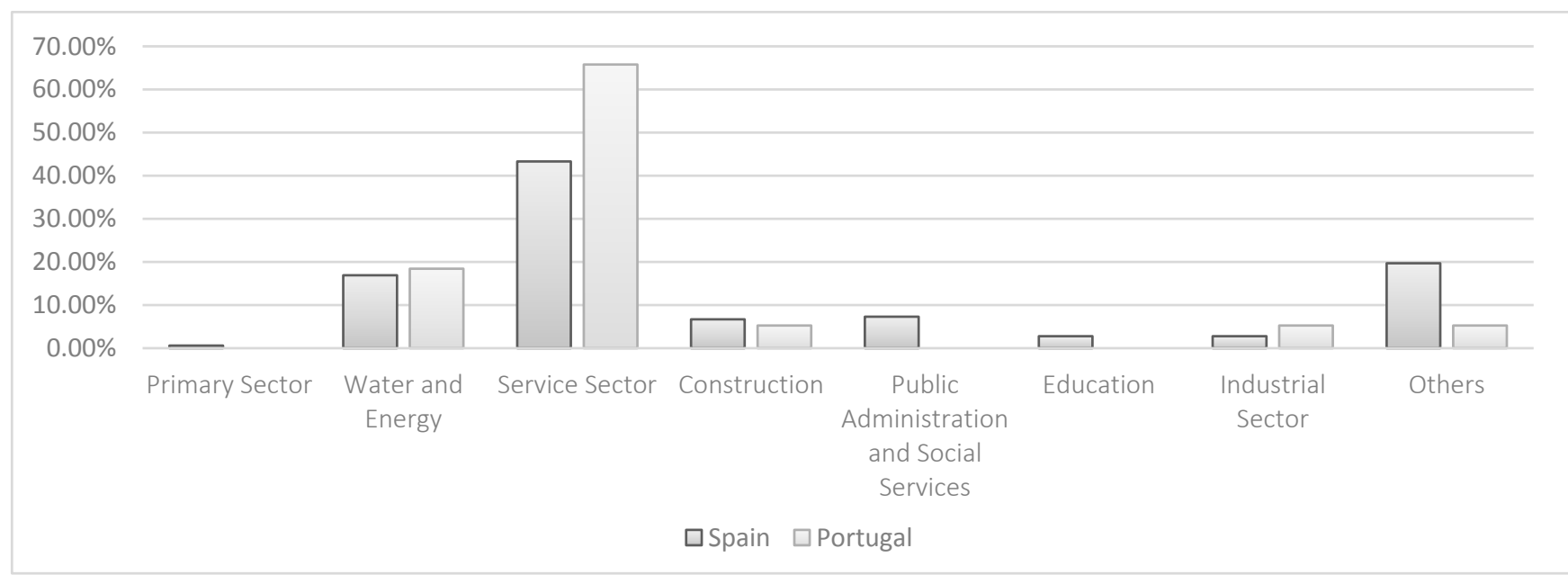

Figure 1. Distribution of companies per type in Spain and Portugal.

While Water and Energy as well as construction share similar trends, it is in Education and Public Administration and Social Service that Portugal lacks a significant distribution of companies. On the other hand, the Service Sector in Portugal is much more predominant. For this paper, a distribution of public companies of 3.85 per cent, and private companies 73.08 per cent was considered. No significant 
differences in the patterns of distribution of firms by sector type were found ( $p$-value $=0.10$ ). A further assessment on the size of companies (Figure 2) is depicted below.

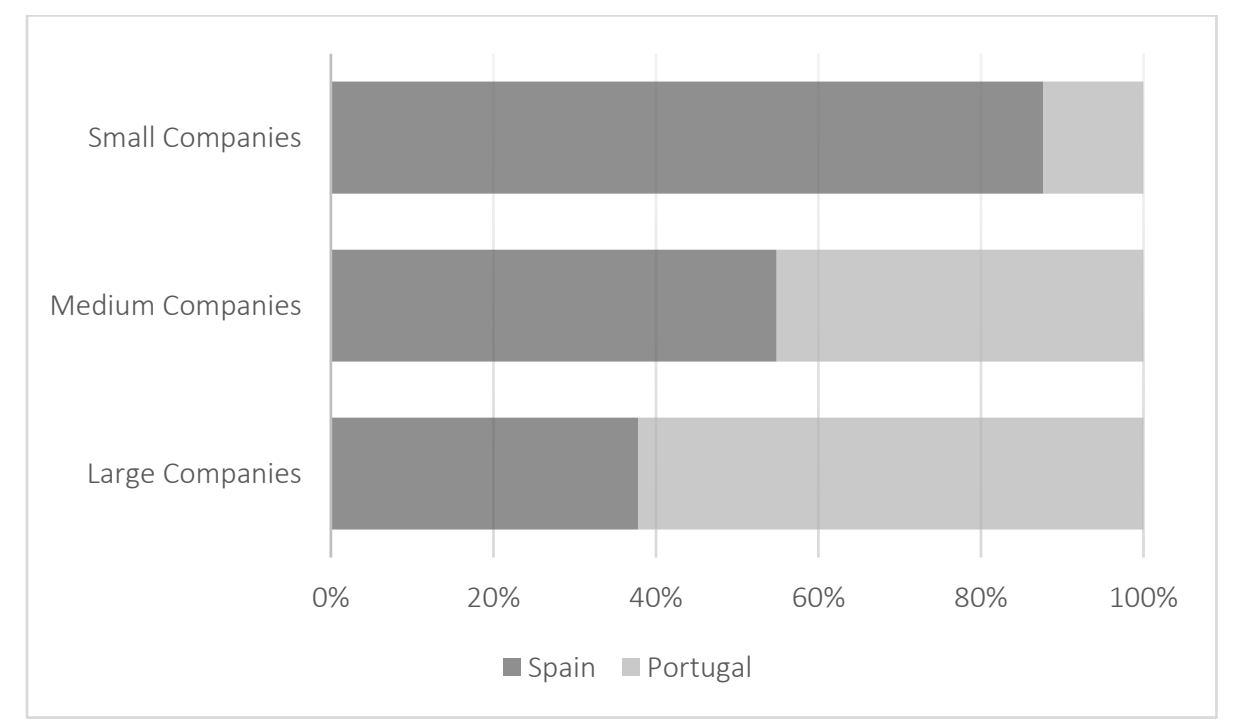

Figure 2. Difference in company size and structure in Spain and Portugal.

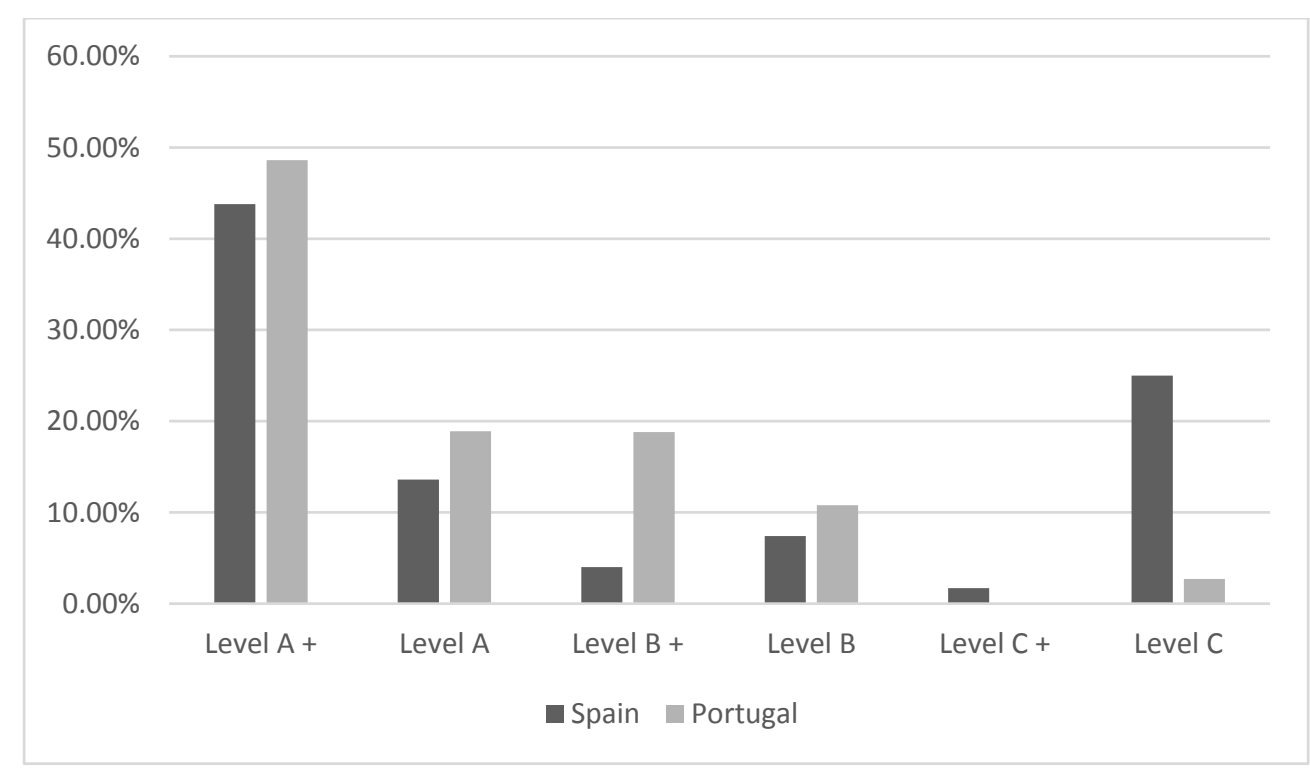

Figure 3. Distribution of classification level for Spain and Portugal.

Significant differences are registered when comparing size and distribution of these businesses. Smaller companies, for instance, a much more predominant in Spain, while the interviewed companies that are larger, prevail in Portugal. Further information in relation to the type of report in Portugal were registered. G3 reports accounted for $40.5 \%$ while 59.5\% were G3.1. In Spain, 44.9\% were present as G3 reports while $55.1 \%$ corresponded to G3.1. No significant differences were registered in the distribution of firms by report type, when comparing both countries ( $p$-value $=0.70)$. A closer analysis of the application level in Portugal allowed assessing that Level $\mathrm{A}+$ is the most common level in both countries, giving a consistent reply to forty-nine core indicators which are externally verified. The plus sign corresponds to external assurance in the classification process (Figure 3). 
The assurance of external evaluation within the companies shows that sustainability is integrated into the business model of these companies, allowing a robust system of information collection, retrieval and performance indicators. Mechanism for identifying main economic, environmental and social impacts are put into place, as well as communicated to stakeholders regarding key strategies, policies, and goals. Regarding the Status of the report, in 2011, 34.2\% of companies in Portugal were GRI-checked, $42.1 \%$ third-part checked, only $21.1 \%$ self-declared and $0 \%$ undeclared. In Spain, in $2011,47.4 \%$ of companies were GRI-checked, 22.4\% third-part checked, 26.7\% self-declared and $3.4 \%$ undeclared.

\subsection{Statistical Methods}

Principal Components Analysis (PCA) and Factor Analysis (FA) have been widely used, but prove inadequate for binary data. To understand the sustainability gradients (or latent composite indexes) of the entities and their relation to the observed characteristics and its graphical representation, an algorithm, as proposed by Vicente-Villardon and others [14], is applied. This algorithm is later extended by an integrated approach as suggested by Demey and others [15]. This combinatory method, comprises a principal coordinates Analysis (PCoA) and Logistic Regression (LR) to construct an External Logistic Biplot. In the step of PCoA, we use the Simple Matching Similarity index, for dichotomous data.

According to [16], the algorithm is closely related to Factor Analysis for Binary Data, Latent Trait Analysis or Item Response Theory; it is also closely related to biplots, allowing for a simultaneous graphical representation of the companies and sustainability indexes that makes the interpretation easier and permits a visual inference of the exploration of the data matrix.

To create clusters we use Ward's minimum variance method, an agglomerative hierarchical clustering procedure, where the criterion for choosing the pair of clusters to merge at each step is based on the optimal value of an objective function, the error sum of squares, with the ordination scores from the Logistic Biplot.

A computer program, based on Matlab code, for implementing these methods is available and can be obtained from the website [17].

The technique presents the companies as points and the sustainability indexes as vectors on a scattergram as a mean of exploring the main characteristics of the data set. Some additional information about the goodness of fit of each index is also provided. This method has been used by $[18,19]$, to analyze Regional Innovation Performance in Portugal, and [20-23], in order to investigate the extent to which different international companies disclose indicators on greenhouse gas emissions.

The methodological approach is based on a complex algorithm which applies a combination of Principal Coordinates Analysis (PCoA) and Logistic Regression (LR) to construct an External Logistic Biplot (ELB). This has been integrated in in previous research efficiently $[2,19,20]$ allowing to measure the behavioral patterns of innovation for different regions.

The algorithm starts with a PCoA to order the companies in the Euclidean space based on the latent gradients. Secondly, this algorithm, by means of a logistic regression model for each variable, by using a latent gradient, is used for independent variables. Because the principal coordinate scores can be represented as points on the map, geometrically the regression coefficients are vectors indicating the directions which best predict the probability of presence of each attribute. 
Those variables related to the ordering obtained in PCoA are ordered in a diagram which best predicts the probability of the presence of each company. The next step of the algorithm consists of adjusting a logistic regression model (LRM) for each variable by using the latent gradients as independent variables. According to the geometry of the Linear Biplot for binary data, in which the responses along the dimensions are logistic, each variable represented by its direction through the origin.

For each attribute, the ordination diagram is divided into two separate regions predicting presence or absence, while the two regions are separated by a line that is perpendicular to the attribute vector in the Biplot and cuts the vector at the point predicting 0.5 . The attributes associated with the configuration are those that predict the respective presences adequately.

Measures of the quality of the representation of units, and variables related to the graphical representation, are also calculated in this framework. As the representation is centered at the origin, the variability of each unit is measured by its squared distance to the center, so that the quality of representation can be measured by the ratio between the squared distance in the reduced dimension and the squared distance in the complete space. The quality of representation of each variable is measured as a combination of three indexes: the $p$-value of the logistic regression, in order to test the relation of the solution and each variable (using the deviance); the Nagelkerke-R squared; and the percentage of correct classifications, using 0.5 as a cut-off point for the expected probability. As a way to identify which gradient (dimension) is mostly related to each variable, the cosine of the angle of the vector representing the variable and the dimension is calculated. The variable is more related to a particular gradient when the absolute value of the cosine is higher than the cosine for other gradients. Then, to produce a composed solution, a Voronoi diagram of the geometrical relationships is presented determined by distances to a specified discrete set of points, for which centroids result from a k-means cluster analysis of the ELB coordinates.

The main aim of this approach is to contribute to the evaluation of how companies are getting increasingly involved in assessing sustainability by proposing a tool able to compare them with each other and localize the individual fragilities in reporting indicators related to such assessments. The fact that cluster configurations are provided helps to generate proposals for policy makers once they are able to observe meaningful sets of specific behaviors that can be target addressed.

In specific analytical terms the plot is interpreted according to the following rules:

- Distances among companies points on the scattergram are inversely related to their profiles similarities, i.e., close companies have similar characteristics.

- The angle between vectors (variables) indicates the degree of association between the variables: the acute (small) angles indicate that the variables are closely related, that is, when a company presents one of the characteristics it also presents the other one and vice versa.

- The angles between vectors representing the variables and factorial axis, estimate the degree of the relation between the variable and the latent dimension. Taking into account that the horizontal axis is the one which always accounts for most information, variables forming acute angles with the first axis are the more relevant to ordinate the companies in relation to the more important gradient of sustainability; that is to classify companies according sustainability.

- The projections of the companies onto the vector representing the variables, estimate the expected probability of the characteristic for that company given its combination of characteristics. 
- The length of the vector that represents each variable indicates the discriminating power of the variable in separating the companies. Shorter vectors are those with the greatest discriminatory power (as long as their information is adequately represented on the plot).

\section{Analysis of Results}

\subsection{Exploratory Analysis}

The sustainability core indicators most disclosed by the 216 companies on the Sustainability Reports (GRI) and/or on their web pages, in 2011, are: Economic EC1 (90.7\%) Direct economic value generated and distributed, including revenues, operating costs, employee compensation, donations and other community investments, retained earnings, and payments to capital providers and governments, Environmental EN8 (81.9\%) Total water withdrawal by source; Society SO1 (68.1\%) Percentage of operations with implemented local community engagement, impact assessments, and development programs and Product responsibility PR3 (69.0\%) Type of product and service information required by procedures and percentage of significant products and services subject to such information requirements.
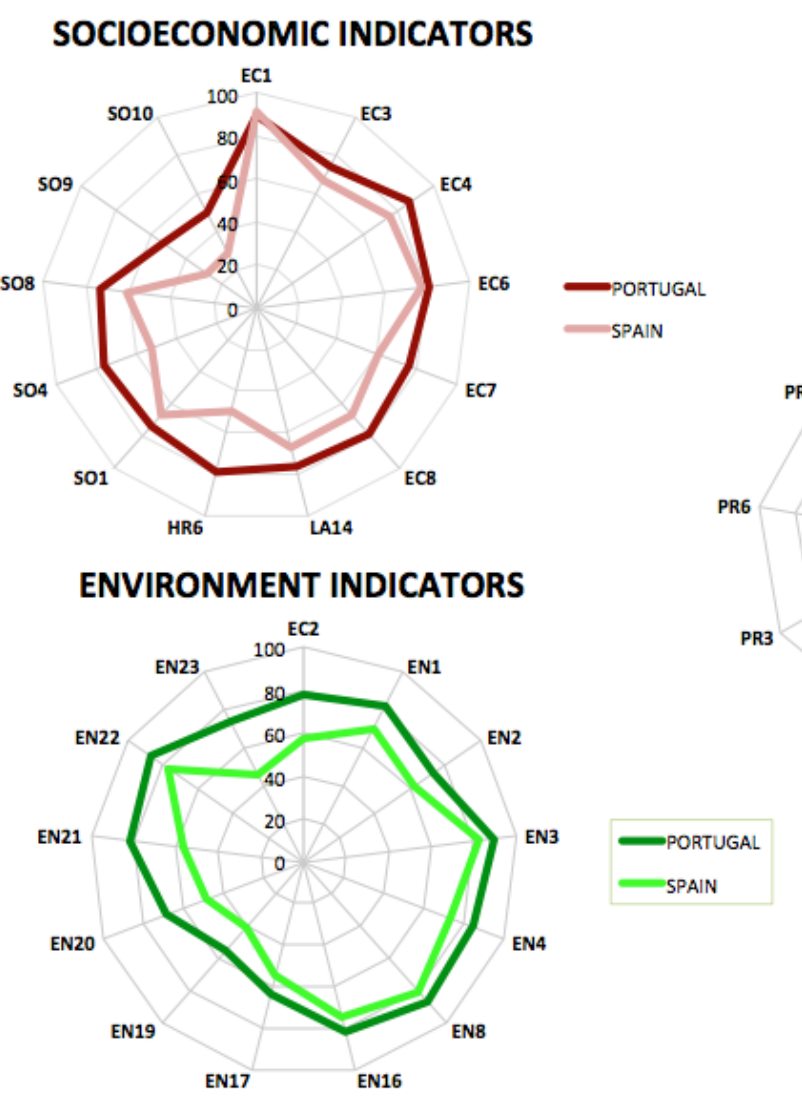

\section{INSTITUTIONAL INDICATORS}

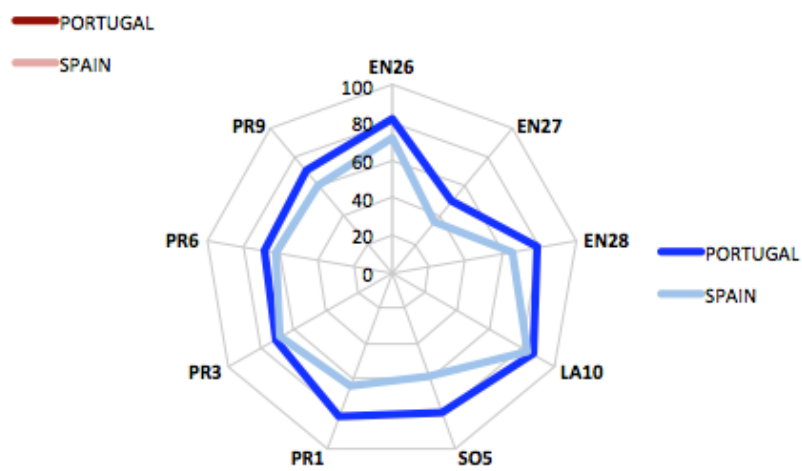

Figure 4. Spider graph. Reporting (\%) for core indicator conforming Socioeconomics, Environment and Institutional Dimensions of the Sustainability, in Spain and Portugal.

In the opposite direction, that is, the indicators less frequently disclosed by companies, were Economic EC2 (61.1\%), financial implications and other risks and opportunities for the organization's activities due to climate change; Environmental EN27 (38.0\%), percentage of products sold and their packaging materials that are reclaimed by category; Society SO9 (32.4\%), operations with significant 
potential or actual negative impacts on local communities; SO10 (32.4\%), prevention and mitigation measures implemented in operations with significant potential or actual negative impacts on local communities; and and Product responsibility PR9 (62.0\%), monetary value of significant fines for noncompliance with laws and regulations concerning the provision and use of products and services. The distribution in Spain and Portugal, for the different indices, can be consulted in Figure 4.

\subsection{Logistic Biplot with External Information}

\subsubsection{Gradients of Sustainability}

As a mean to obtain the main gradients of sustainability and their relation to the observed characteristics and its graphical representation, we apply the External Logistic Biplot algorithm [12-15]. The technique presents the companies as points and the indicators as vectors on a scattergram as a mean of capturing the main characteristics of the data set. The biplot representation is useful not only for describing the similarity among the companies but also for describing the variables responsible for the similarities and for describing the relations among the variables in order to summarize their common information in latent gradients to capture the information contained in the data.

The first principal plane (2D solutions) accounts for $51 \%$ of the variability. The first eigenvalue 20.43 is significantly higher than the second eigenvalue (2.53), meaning that even if the two sustainability gradients are considered, the first (horizontal) dimension accounts for most of the information. The overall goodness of fit (average of the goodness of fit for each variable) as a percentage of correct classification in the biplot is $89.47 \%$, so the two dimensional solution is sufficient to explore the main features of the data. Nevertheless it is possible to explore the three dimensional representation. The biplot solution is shown in Figure 5.

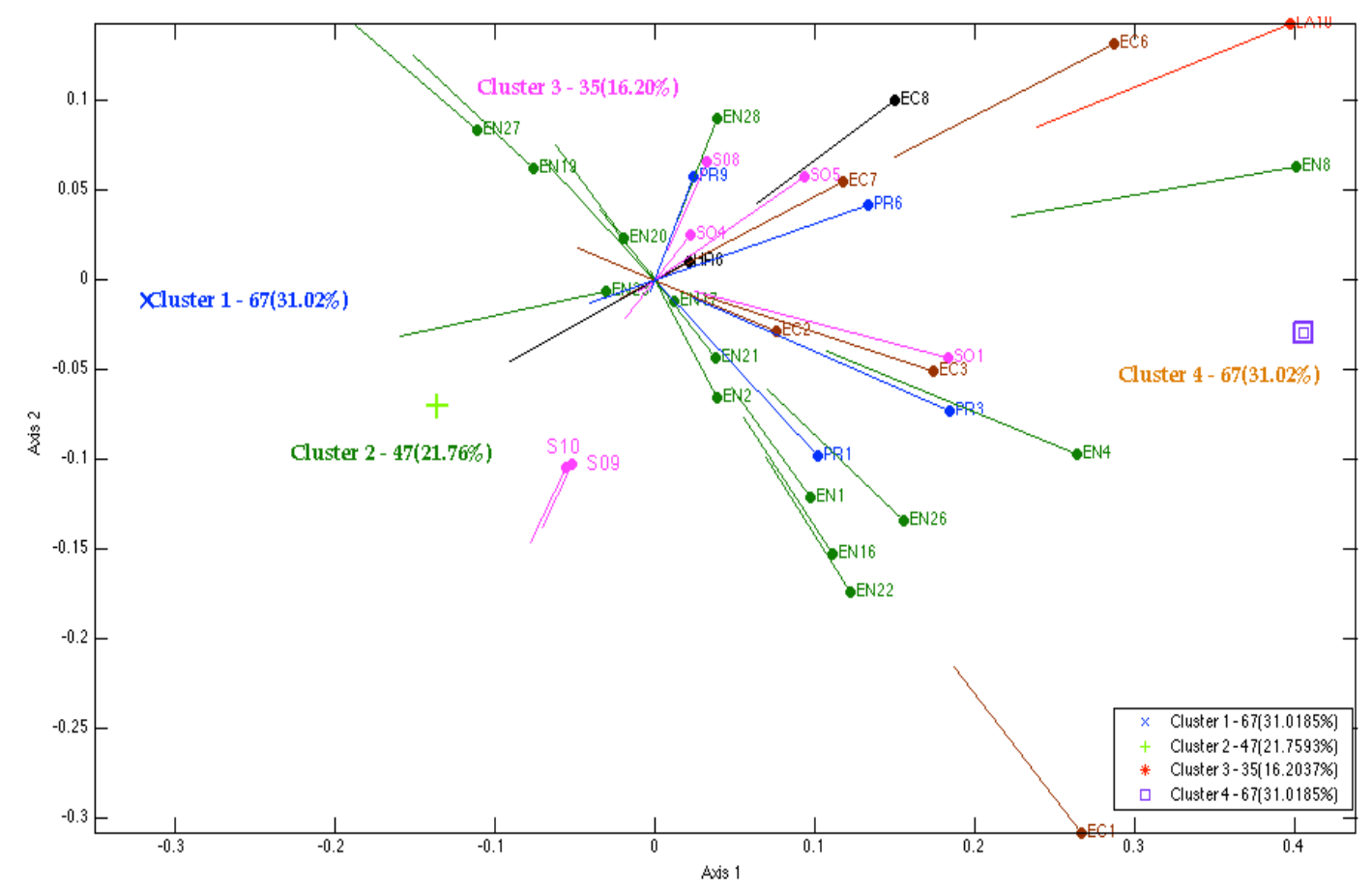

Figure 5. Two dimensional logistic columns Biplot, based on sustainability data from Spanish and Portuguese Companies. 
Several measures are shown in Table 3: Significance of the deviance in the logistic fit, $\mathrm{R}^{2}$, the percentage of correct classifications obtained from the expected probabilities (the prediction is presence if the expected probability is higher than 0.5 and absence otherwise) and some indicators of the relations between the indicators and the gradients (only variables with $\mathrm{R}^{2}$ higher than 0.5 are shown on the graph). Cosines of the angles formed by variables with the respective factor axes are also in the table and information about the maximum cosine Axis.

Table 3. Goodness of fit indicators Global Reporting Initiative (GRI).

\begin{tabular}{|c|c|c|c|c|c|c|c|}
\hline & Deviance & $p$-value & $\mathbf{R}^{2}$ & \% Correct Classification & Cos Axi 1 & Cos Axi 2 & $\operatorname{Max} \operatorname{Cos} A x i$ \\
\hline EC1 & 9.04 & $<0.05$ & 0.56 & 90.28 & 0.65 & -0.75 & 2 \\
\hline EC2 & 8.39 & $<0.05$ & 0.69 & 86.57 & 0.94 & -0.35 & 1 \\
\hline EC3 & 7.47 & $<0.05$ & 0.68 & 87.96 & 0.96 & -0.28 & 1 \\
\hline EC4 & 5.69 & $<0.05$ & 0.44 & 78.24 & 0.94 & 0.42 & 1 \\
\hline EC6 & 7.36 & $<0.05$ & 0.62 & 82.41 & 0.91 & 0.42 & 1 \\
\hline EC7 & 7.23 & $<0.05$ & 0.62 & 86.11 & 0.83 & 0.55 & 1 \\
\hline EC8 & 10.60 & $<0.05$ & 0.80 & 87.96 & 0.63 & -0.78 & 2 \\
\hline EN1 & 14.13 & $<0.05$ & 0.83 & 89.81 & 0.51 & -0.86 & 2 \\
\hline EN2 & 13.51 & $<0.05$ & 0.69 & 87.04 & 0.94 & -0.34 & 1 \\
\hline EN3 & 6.84 & $<0.05$ & 0.39 & 81.02 & 0.99 & 0.15 & 1 \\
\hline EN4 & 6.68 & $<0.05$ & 0.61 & 83.80 & 0.59 & -0.81 & 2 \\
\hline EN8 & 6.20 & $<0.05$ & 0.56 & 82.87 & 0.72 & -0.69 & 1 \\
\hline EN16 & 11.67 & $<0.05$ & 0.72 & 86.11 & -0.77 & 0.64 & 1 \\
\hline EN17 & 9.70 & $<0.05$ & 0.63 & 83.80 & -0.64 & 0.77 & 2 \\
\hline EN19 & 11.26 & $<0.05$ & 0.69 & 85.18 & 0.66 & -0.75 & 2 \\
\hline EN20 & 16.53 & $<0.05$ & 0.79 & 88.43 & 0.57 & -0.82 & 2 \\
\hline EN21 & 10.03 & $<0.05$ & 0.63 & 83.33 & -0.98 & -0.19 & 1 \\
\hline EN22 & 12.01 & $<0.05$ & 0.73 & 87.50 & 0.76 & -0.65 & 1 \\
\hline EN23 & 8.42 & $<0.05$ & 0.68 & 84.72 & -0.80 & 0.60 & 1 \\
\hline EN26 & 9.84 & $<0.05$ & 0.73 & 87.04 & 0.40 & 0.92 & 2 \\
\hline EN27 & 11.51 & $<0.05$ & 0.71 & 87.04 & 0.94 & 0.34 & 1 \\
\hline EN28 & 17.01 & $<0.05$ & 0.75 & 87.96 & 0.89 & 0.44 & 1 \\
\hline LA10 & 6.62 & $<0.05$ & 0.55 & 83.33 & 0.97 & -0.23 & 1 \\
\hline LA14 & 5.40 & $<0.05$ & 0.49 & 81.02 & 0.66 & 0.75 & 2 \\
\hline HR6 & 8.82 & $<0.05$ & 0.69 & 85.65 & 0.85 & 0.53 & 1 \\
\hline S01 & 6.81 & $<0.05$ & 0.63 & 87.04 & 0.44 & 0.90 & 2 \\
\hline S04 & 17.80 & $<0.05$ & 0.86 & 93.06 & -0.45 & -0.89 & 2 \\
\hline S05 & 9.05 & $<0.05$ & 0.70 & 84.72 & -0.47 & -0.88 & 2 \\
\hline S08 & 20.04 & $<0.05$ & 0.84 & 89.35 & 0.72 & -0.69 & 1 \\
\hline S09 & 27.39 & $<0.05$ & 0.93 & 96.30 & 0.93 & -0.37 & 1 \\
\hline S010 & 23.25 & $<0.05$ & 0.89 & 95.37 & 0.95 & 0.30 & 1 \\
\hline PR1 & 8.07 & $<0.05$ & 0.58 & 84.72 & 0.39 & 0.92 & 2 \\
\hline PR3 & 6.48 & $<0.05$ & 0.58 & 81.48 & 0.65 & -0.75 & 2 \\
\hline PR6 & 6.12 & $<0.05$ & 0.55 & 81.02 & 0.94 & -0.35 & 1 \\
\hline PR9 & 15.85 & $<0.05$ & 0.69 & 86.11 & 0.96 & -0.28 & 1 \\
\hline
\end{tabular}

All variables have a significant ( $p$-value $<0.01$ ), i.e., all the variables are significantly related to the observed ordination of the companies. The variables that exceed an $\mathrm{R}^{2}$ of 0.80 can be considered the most relevant variables to interpret the ordination of the companies on the scattergram, and consist of: 
EC8 (0.80), IEN1 (0.83), SO4 (0.86), SO8 (0.84), SO9 (0.93), S10 (0.89). The variables with a lower predictive value $\mathrm{R}^{2}$ are EC4 (0.44), EN3 (0.39), LA14 (0.49), and thus are less useful for the classification of the companies in the two dimensional solution. The rest of the variables have intermediate predictive values (from 0.5 to 0.8 ).

The cosines of the angles formed by variables with the respective factor axes or gradients are also shown in Table 3. For the variables with a high $\mathrm{R}^{2}$, the cosines of the angles are useful to interpret how variables are related to each gradient.

Table 3 shows that gradient (axis) 1 is mainly related to variables EC2, EC3, EC4, EC6, (Economics), EN2, EN3, EN21, EN27, (Environmental), LA10 (Labor Practice), S09, S010 (Society) PR6 and PR10 (Product responsibility) and the gradient associated with axis 2 is related to variables EN1, EN4 (Environmental), S01, S04, S05 (society) and PR1 (Product). This means that the presence of the indicators mentioned above is less likely in companies that are located to the right on the spatial representation, since the corresponding segment points to the negative direction of the axis. Observe that the gradients share some of the variables meaning that are not well defined. From the representation we can see that this is due to the fact that the main gradients defined for the variables are not parallel to the axis.

In summary, we have found two main gradients. The first one is related to economics performance and market presence, environmental aspects, materials and energy, emissions, effluents and waste, training and education, marketing communications and compliance and the second one is related to society and product responsibility and some aspects of environment.

The segments representing the indicators point into four directions: two of them at an acute angle with the factorial $\mathrm{X}$ axes that means a positive correlation among all these indicators and this factorial gradient, differing only in the position along the gradient. Drawing an imaginary line passing through these directions we can interpret the positions of the variables on it, for example, indicators EN27, EN19 and EN20 are more difficult to find in the studied sample and usually appear together, while items, EN22, EN16, EN1 and EN26 are most frequently listed. Similar reasoning should be made for the other indicators.

By assessing the biplot graphic, we can describe the four directions in which sustainability indicators are grouped:

(i) One of them consists of environmental indicators: (EN1, EN2 Materials), (EN16, EN17, EN19, EN20, EN21, EN22 Emissions, Effluents, and Waste), (EN26 and EN27 Products and Services), all with high positive correlation, that means that when one of them is reported all the rest are also reported. PR1 (Health and safety impacts of products) and EC1 (Economic Performance), are strongly related to the previous group of environmental indicators, but they are indicators with low discriminating power because most companies report them.

(ii) EN8 (Water) and EN23 (Total number and volume of significant spills.) which are also environmental indicators are strongly related to each other, but have a weak inverse relationship with the previous group: that is, when the companies report these indices, they generally do not report indices belonging to the previous group. The latter two environmental indicators covary strongly with socio-economic aspects, HR6 (Child Labor), (EC6, EC7, Market Presence), EC8 (Indirect Economic Impacts) and institutional aspects, SO5 (Public Policy), PR6 (Marketing Communications) and LA10 (Training and Education). 
(iii) Another group of indices that strongly covariance between them and present a positive, but weaker relationship, with the two previously mentioned groups, is formed by Socioeconomics aspects EC3 (Coverage of the organization's defined benefit plan obligations), SO1 (Local community engagement), Institutionalize PR3 (Product and Service Labelling), and Environment (EN4 Energy and EC2 Financial implications due to climate change.)

(iv) The fourth group consists of the indices EN28 and SO8 (Compliance, monetary and non-monetary sanctions for non-compliance with environmental laws and regulation, respectively), PR9 (Compliance monetary value for non-compliance with laws and regulations concerning the provision and use of products and services), SO4 (Actions taken in response to incidents of Corruption), SO9 and SO10 (Negative impacts on local communities). SO9 and SO10 are two of the indices added in G3.1. This group of indices are more correlated with the second factorial axis (vertical), and thus forms the second gradient sustainability. According to this gradient, it is possible to order the companies projecting them onto this second axis. In this way it is possible to order the companies according to the type of the report, companies with G3 (on the top) and companies with G3.1, down. In addition, it is possible to differentiate which are penalized for not complying with the law, those that comply with legislation.

\subsubsection{Clusters of Sustainability}

To create clusters of companies with a similar profile of sustainability we use hierarchical clustering Ward's method with the ordination scores from the Logistic Biplot.

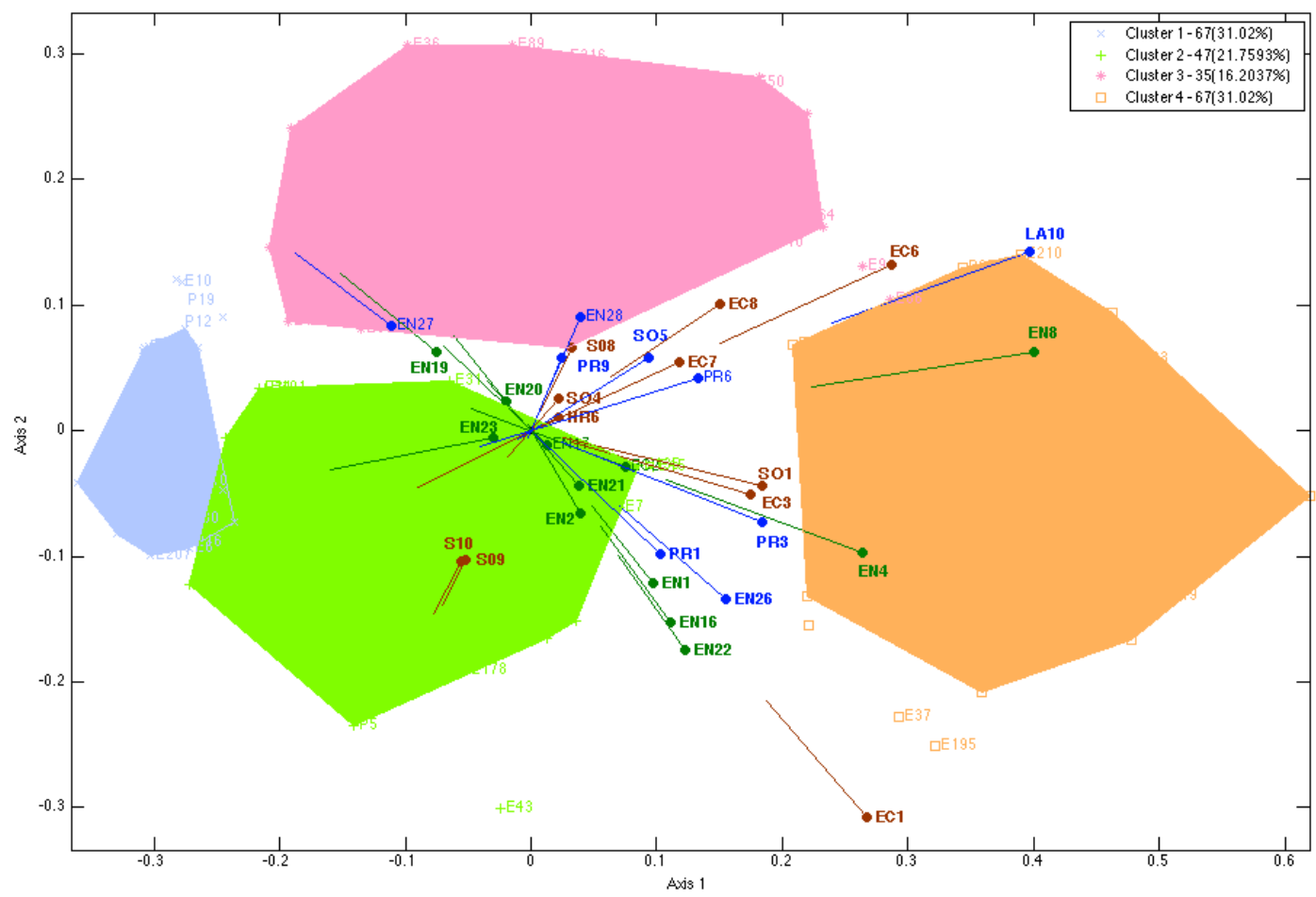

Figure 6. Two-dimensional External LOGISTIC BIPLOT with clusters. In the step of PCoA we use Simple Matching similarity index, for dichotomous data, and agglomerative Ward method for clustering. Spanish and Portuguese companies (Socioeconomic indicators in brown, environmental indicators in green, institutional indicators in blue). 
In Figure 6, the companies in each cluster have been colored respectively and a polygon containing all the companies (convex hull) has been drawn. Four clusters were described and represented onto the Euclidean map of this figure.

There are some indicators whose goodness of fit is not very high because their variability is not high (for example EC1 that is an indicator reported by nearly all companies) or because we need more dimensions to describe the whole set of indicators. Nevertheless, the two dimensional solution is enough to account for the most relevant information:

(i) Cluster 1 (in blue) with 67 companies (31\%) is the cluster formed by the companies reporting the most sustainability indices, i.e., this cluster contains the companies with highest level of contribution towards sustainability. The convex hull occupies a small area, not because the cluster is formed by few companies, but because they all have a very similar profile based on the fact that all companies reported all indicators. As can be seen, if we project the cluster on each and every one of the indicators, the projection belongs to the region of presence. In Table 4, it is possible that all companies belonging to Cluster 1, the $100 \%$ rate reported the indexes EC1, EC6, EN8, EN21, EN22, EN23, EN26, EN28, SO4 and PR3. More than 90\% of the firms in this cluster report all other indices except SO9 that is reported by the $67.16 \%$ and SO10 that is reported by $65.67 \%$ of the firms in this cluster. It should be noted that these two indices are incorporated in the G3.1.

(ii) Companies belonging to Cluster 2 (in green), 47 companies (21.76\%), and companies belonging to Cluster 3 (in pink), 34 companies (15.74\%) and companies belonging to Cluster 4 (in orange), 68 companies (31.48\%), occupy similar positions in relation to the horizontal gradient sustainability but are differentiated by axis 2 . Cluster 2 can be considered second in relation to the level of sustainability. In Cluster 2, the only indicator EC8, is reported by $100 \%$ of the firms in this cluster, between $90 \%$ and $99 \%$ of companies in this cluster reported EC1, EC4, EC6, EN4, EN8, EN22, LA10, SO4 and SO8. Between $80 \%$ and 90\% companies in this Cluster 2, reported EC2, EC7, EN1, EN3, EN16, EN26, EN28, LA14, SO1, SO5 and PR9. Between 70 and $80 \%$ of companies in this cluster reported EN2, HR6, PR3 and PR6. Less than $30 \%$ of companies in Cluster 2 reported EN19, EN20 and EN27. The two indices included in the G3.1, SO9 and SO10, are only reported by $47 \%$ of companies in this cluster.

(iii) No sustainability index was reported by $100 \%$ of companies in Cluster 3 (in pink). The EC1, EN1, EN2, EN16, EN22 and LA10 indices are reported by more than $90 \%$ of the firms in the cluster. Between $80 \%$ and $90 \%$ of the companies in Cluster 3 reported the EC6, EN3, EN8, EN26, PR1 SO1 and indexes. Between 70 and $80 \%$ of companies in Cluster 3 reported the EC3, EN4, EN17, EN20, EN21 and PR3 indexes. Less than $30 \%$ of companies in Cluster 3 reported EN23, EN28, SO4, SO9, SO10 and PR9. Note that while 47\% of companies in Cluster 2 reported the two new indices G3.1, SO9, SO10, but in this cluster only reported the $8.57 \%$ and $11.43 \%$.

(iv) Cluster 4 (in orange) with 67 companies (31\%) is the cluster formed by firms with lower levels of contribution towards sustainability, i.e., consists of firms with the least indices reported. Only EC1 index is reported by a 73\% increase of companies in this cluster, all other indices are reported by a significantly lower percentage of companies. 
Table 4. Characterization of the four sustainability clusters (Spain and Portugal) between brackets number of companies, without brackets $\%$ calculated relative to the cluster total.

\begin{tabular}{|c|c|c|c|c|c|}
\hline$N=216$ & $\mathbf{n}$ & $\begin{array}{c}\text { Cluster } 1 \\
67 \\
\end{array}$ & $\begin{array}{c}\text { Cluster } 2 \\
47 \\
\end{array}$ & $\begin{array}{c}\text { Cluster } 3 \\
34 \\
\end{array}$ & $\begin{array}{c}\text { Cluster } 4 \\
68 \\
\end{array}$ \\
\hline \multirow[t]{3}{*}{ Country $N=216$} & Spain & (49) $73.1 \%$ & (36) $76.6 \%$ & (32) $94.1 \%$ & (61) $89.7 \%$ \\
\hline & Portugal & (18) $26.9 \%$ & (11) $23.4 \%$ & (2) $5.9 \%$ & (7) $10.3 \%$ \\
\hline & & & & & $p=0.013$ \\
\hline $\begin{array}{c}\text { n Spain = } 178 \\
\text { n Portugal }=38\end{array}$ & $\begin{array}{l}\% \text { calculated } \\
\text { relative to } \\
\text { its country total }\end{array}$ & $27.5 \% S / 47.4 \% P$ & $20.2 \% S / 28.9 \% P$ & $18.0 \% \mathrm{~S} / 5.3 \% \mathrm{P}$ & $34.3 \% \mathrm{~S} / 18.4 \% P$ \\
\hline \multirow{3}{*}{$\begin{array}{l}\text { Report } \\
n=155\end{array}$} & GRI-G3 & (13) $34.2 \%$ & (10) $30.3 \%$ & (13) $56.5 \%$ & (32) $52.5 \%$ \\
\hline & GRI-G3.1 & (25) $65.8 \%$ & (23) $69.7 \%$ & (10) $43.5 \%$ & (29) $47.5 \%$ \\
\hline & & & & & $p=0.065$ \\
\hline \multirow{9}{*}{$\begin{array}{l}\text { Sector } \\
n=216\end{array}$} & Primary Sector & (0) $0 \%$ & (0) $0 \%$ & (0) $0 \%$ & (1) $1.5 \%$ \\
\hline & Industry Sector & (1) $1.5 \%$ & (2) $4.3 \%$ & (3) $8.8 \%$ & (1) $1.5 \%$ \\
\hline & Water Energy & (19) $28.4 \%$ & (8) $17 \%$ & (5) $14.7 \%$ & (5) $7.4 \%$ \\
\hline & CoNstruction & (5) $7.5 \%$ & (3) $6.4 \%$ & (2) $5.9 \%$ & (4) $5.9 \%$ \\
\hline & Services Sector & (32) $47.8 \%$ & (24) $51.1 \%$ & (13) $38.2 \%$ & (33) $48.5 \%$ \\
\hline & AdmSocServic & (2) $3.0 \%$ & (3) $6.4 \%$ & (5) $14.7 \%$ & (3) $4.4 \%$ \\
\hline & EDucation & (1) $1.5 \%$ & (0) $0 \%$ & (0) $0 \%$ & (4) $5.9 \%$ \\
\hline & OThers & (7) $10.4 \%$ & (7) $14.9 \%$ & (6) $17.6 \%$ & (17) $25.0 \%$ \\
\hline & & & & & $p=0.053$ \\
\hline \multirow{4}{*}{$\begin{array}{c}\text { Size } \\
n=216\end{array}$} & Large & (60) $89.6 \%$ & (32) $68.1 \%$ & (18) $52.9 \%$ & (17) $25.0 \%$ \\
\hline & Medium & (4) $6.0 \%$ & (7) $14.9 \%$ & (6) $17.6 \%$ & (3) $4.4 \%$ \\
\hline & Small & (3) $4.5 \%$ & (8) $17 \%$ & (10) $29.4 \%$ & (48) $70.6 \%$ \\
\hline & & & & & $p=0.000$ \\
\hline \multirow{4}{*}{$\begin{array}{c}\text { Type } \\
\mathrm{n}=100\end{array}$} & Private & (18) $69.2 \%$ & (7) $58.3 \%$ & (6) $42.9 \%$ & (35) $72.9 \%$ \\
\hline & Public & (4) $15.4 \%$ & (0) $0.0 \%$ & (1) $7.1 \%$ & (1) $2.1 \%$ \\
\hline & Other & (4) $15.4 \%$ & (5) $41.7 \%$ & (7) $50 \%$ & (12) $25 \%$ \\
\hline & & & & & $p=0.017$ \\
\hline \multirow{5}{*}{$\begin{array}{c}\text { Status } \\
\mathrm{n}=154\end{array}$} & GRI- Checked & (20) $51.3 \%$ & (21) $63.6 \%$ & (15) $65.2 \%$ & (12) $20.3 \%$ \\
\hline & $\begin{array}{l}\text { Third Part } \\
\text { checked }\end{array}$ & (13) $33.3 \%$ & (8) $24.2 \%$ & (3) $13.0 \%$ & (18) $30.5 \%$ \\
\hline & Self declared & (6) $15.4 \%$ & (4) $12.1 \%$ & (4) $17.4 \%$ & (25) $42.4 \%$ \\
\hline & Undeclared & (0) $0.0 \%$ & (0) $0.0 \%$ & (1) $4.3 \%$ & (4) $6.8 \%$ \\
\hline & & & & & $p=0.000$ \\
\hline \multirow{8}{*}{$\begin{array}{c}\text { Applicat } \\
\text { Level } \\
\mathrm{n}=155\end{array}$} & $\mathrm{C}$ & (0) $0.0 \%$ & (1) $3.0 \%$ & (3) 13.05 & (38) $63.3 \%$ \\
\hline & $\mathrm{C}+$ & (0) $0.0 \%$ & (0) $0.0 \%$ & (0) $0.0 \%$ & (3) $5.0 \%$ \\
\hline & $\mathrm{B}$ & (1) $2.6 \%$ & (3) $9.1 \%$ & (2) $8.7 \%$ & (6) $10.0 \%$ \\
\hline & $\mathrm{B}+$ & (1) $2.6 \%$ & (5) $15.2 \%$ & (3) $13.0 \%$ & (4) $6.7 \%$ \\
\hline & A & (10) $25.6 \%$ & (7) $21.2 \%$ & (4) $17.4 \%$ & (0) $0.0 \%$ \\
\hline & $\mathrm{A}+$ & (27) $69.2 \%$ & (17) $51.5 \%$ & (11) $47.8 \%$ & (3) $5.0 \%$ \\
\hline & Undeclared & (0) $0.0 \%$ & (0) $0.0 \%$ & (0) $0.0 \%$ & (6) $10.0 \%$ \\
\hline & & & & & $p=0.000$ \\
\hline
\end{tabular}


From this information and analyzing, in detail, the companies within each cluster, as well as the country to which they belong to and the sector to which they are dedicated, Type of Report, Type of companies, Status of the Report and Level of Application, found the following characterization, for the four sustainability clusters.

\section{Discussion of Results}

The maximum sustainability cluster (Cluster 1(blue) in Figure 5) is formed mainly by Spanish companies $(73.1 \%)$, large $(89.6 \%)$, private companies $(69.2 \%)$, belonging to Services Sector (47.8\%) and Water and Energy sector (28.4\%), GRI-Checked (51.3\%), mostly reporting GRI-G3.1 (65.8\%), with application level $\mathrm{A}+(69.2 \%)$ and $\mathrm{A}(25.6 \%)$.

Nevertheless, it is important to highlight that Portuguese companies have higher level of sustainability because in Spain, only the $27.5 \%$ of the companies belong to the cluster of maximum sustainability, but in Portugal, $47.4 \%$ of the companies belong to the Cluster 1.

Moreover, as we noted above, all companies belonging to Cluster 1, 100\%, reported the indexes EC1, EC6, EN8, EN21, EN22, EN23, EN26, EN28, SO4 and PR3. More than 90\% of the firms in this cluster report all other indices, except SO9 that is reported by the $67.16 \%$ and SO10 that is reported by $65.67 \%$ of the firms in this cluster. See Table 5, bellow. Reported by $100 \%$ of the firms in this cluster are: EN1, EN8, EN21, EN22, EN23, EN26, EN28, SO4.The least reported in this Cluster are SO9 and SO10 which have only been reported by $67.16 \%$ and $65.67 \%$, respectively.

Table 5. Distribution of the indices in the cluster of maximum sustainability (Cluster 1).

\begin{tabular}{|l|l|l|l|l|l|}
\hline \multicolumn{6}{|l|}{ Cluster 1 } \\
\hline EC1 & 95.52 & EC2 & 95.52 & EN26 & 100.0 \\
\hline EC3 & 97.01 & EN1 & 100 & EN27 & 85.07 \\
\hline EC4 & 98.51 & EN2 & 91.04 & EN28 & 100.0 \\
\hline EC6 & 100.0 & EN3 & 100 & LA10 & 98.51 \\
\hline EC7 & 95.52 & EN4 & 97.02 & SO5 & 98.51 \\
\hline EC8 & 98.51 & EN8 & 100 & PR1 & 95.52 \\
\hline LA14 & 92.54 & EN16 & 98.51 & PR3 & 100.0 \\
\hline HR6 & 97.02 & EN17 & 95.52 & PR6 & 98.51 \\
\hline SO1 & 98.51 & EN19 & 92.54 & & \\
\hline SO4 & 100.0 & EN20 & 98.51 & & \\
\hline SO8 & 95.52 & EN21 & 100 & & \\
\hline SO9 & 67.16 & EN22 & 100 & & \\
\hline SO10 & 65.67 & EN23 & 100 & & \\
\hline
\end{tabular}

Cluster 4 has the lowest level of sustainability (in orange in Figure 5), and is formed mainly by Spanish companies $(52.5 \%)$, small (70.6\%), private companies (72.9\%), belonging to Services Sector (48.5\%), Self-declared (42.4\%), mostly reporting GRI-G3 (52.5\%), with application level C (63.3\%). For companies belonging to Cluster 4, verifies that EN17, EN19, EN20, EN23, EN27, HR6, SO4, indices are reported by less than $10 \%$ of the companies, and none of them reports SO9 and SO10 (G3.1). See more details in Table 4, above. Cluster 2, high-medium level of sustainability, and Cluster 3 , medium-low level of sustainability, have intermediate characteristics. 
We emphasize that the EN17, EN19, EN20, EN23, EN27, HR6, SO4, indices are reported by less than $10 \%$ of the companies, and none of them reports SO9 and SO10 (G3.1). Note that although the percentage of companies in Cluster 4 is the same as that of the companies in the Cluster 1, the hull convex representing it, has a significantly larger surface. This means that although the cluster is formed by the least sustainable companies, there are different levels of sustainability inside the cluster and the reported indices are not the same in all companies.

\section{Conclusions}

The paper supplies two major sets of conclusions. Firstly, we have provided a comprehensive and complete methodology, able to access the global situation on how corporations are contributing to sustainability in a given country and how they are reporting it.

Of course, for the development of such methodology and analyses it was assumed that the act of reporting sustainability by the corporations was a proxy to the concept of sustainability. In addition, it was assumed that increasing corporations' social responsibility slowly reinforces the effective use of actions related to sustainability.

The proposed method is ergonomic and provides evidence to evaluate the contribution of each organization, individually considered or as an element of a group. The general understanding that can be obtained by the evaluation of such a global view may be a great opportunity to the governance structure to reinforce the regulatory links with corporations.

However, for the corporations themselves, the use of this method clarifies their relative position regarding the efforts made by completion and partners and further identifies the social needs as a whole, each individual relative position being promoted in a game of clear increasing social responsibility. By comparing their relative positions, each company would not only learn from others but also tend to report more of their actions, their goal being to be driven further to the plot of the most sustainable ones. From a dynamic point of view, and under no limitations, they all would tend to the same ideal plot.

We have assumed corporations as net contributors to sustainability and this is, of course, very discussable. However, not innocently, it is our belief that sooner or later big corporations (the most powerful productive instruments) will not be able to escape the huge social responsibility they carry and will embrace positively their responsibility to better shape a more sustainable world progressively betting on incentives for environmental innovations and social improvements.

Although an extended multi-country analysis is very relevant, our study focused on Portugal and Spain as a pilot experiment to test the methodology. These two countries have gone through a very strong and dynamic regulation change and economical push in terms of sustainability justifying this interest. By studying a panel of corporations for 2011 we confirm that even in presence of a crumbly environmental regulatory framework, mainly because the control of regulation as well as the financial capacities are lacking, companies have found out endogenous mechanisms to stimulate greener technologies, or other forms to improve their contribution to the broad concept of sustainability. Unexpectedly, we found this more expressive in Portugal then in Spain. Our method also permits, by comparison, to find out which are those more responsible for each country position or each corporation contribution.

More in deep the interpretation of the findings point out to the following behavior from the part of the companies: 
- Reporting on the assessment to sustainability measures is an increasing practice within Portuguese and Spanish corporation, in particular services or water and energy sector. In Portugal more than $60 \%$ of all the reports have origin in the services.

- In relation to size, in Portugal large companies report more; Spanish small companies are more active in recording their results. Most corporations have chosen an A+ kind of assessment, meaning that they are opened to have their data confirmed by external assurance in the classification process.

- When observing the three set of indicators, we can conclude that a few indicators are not meaningful to the reported initiatives. The most expressive examples differ between Portugal and Spain. For the Portuguese case, they are related to effluents and emissions, operations with negative impact on the communities and waste; For Spain, significant missing data is detected in used material in the productive processes, mitigation measures for operations with negative impact on the communities and waste, just like in Portugal.

- Corporation behavior when reporting can be grouped in four groups. The most expressive group contains 67 companies, 49 from Spain and 18 from Portugal. Most of them from the private sector. There is also a significant amount of corporation that do not report fully and we assume they have lower levels of sustainability. Most of them, 90\%, are located in Spain, are small and belong to services.

- Those indicators that are more prompt to be reported are market presence, public policy, usage of materials and water, institutional dimension of products and compliance.

Based on these and other results, companies should try to progress in reporting extensively their activities as means of actively participate GRI and GRI checking. This alone would be already a contribution to policy makers if the proxy between corporation individual sustainability actions and their reporting to, for example, the GRI initiative is assumed. Analysts would increasingly follow public policy measures and confirm their results. However, there are several limitations that this method was not able to overcome, most of which are related to restrictions related to the accuracy of the indicators since their value was not used in the analyses. In this case, the fact that a corporation is providing full information does not mean it will learn exactly how it is acting to improve its efforts towards sustainability.

Finally, our results suggest that mechanisms, endogenous to corporations and national governance systems, were able to stimulate greener technologies in both Portugal and Spain. Although in the presence of contexts of weak exogenous pressures and a fragile environmental regulatory framework, internal inducements could create environmental innovations, encouraged by firms' reactions to their environmental performance.

\section{Acknowledgements}

The authors would like to thank the reviewers for their useful and constructive comments.

\section{Conflicts of Interest}

The authors declare no conflict of interest. 


\section{References}

1. Vaz, E.; Walczynska, A.; Nijkamp, P. Regional challenges in tourist wetland systems: An integrated approach to the Ria Formosa in the Algarve, Portugal, 2013. Reg. Environ. Change 2013, 13, $33-42$.

2. Noronha Vaz, T.; Galindo, P.V.; Vaz, E.; Nijkamp, P. Innovative firms behind the regions: Analysis of regional innovation performance in Portugal by external logistic biplots. Eur. Urban Reg. Stud. 2013, doi:10.1177/0969776412474675.

3. Ghisetti, C.; Quatrato, F. Beyond inducement in climate change: Does environmental performance spur environmental technologies? A regional analysis of cross-sectoral differences. Ecol. Econ. 2013, 96, 99-113.

4. Spangenberg, J.H.; Pfahl, S.; Deller, K. Towards indicators for institutional sustainability: Lessons from an analysis of Agenda 21. Ecol. Indic. 2002, 2, 61-77.

5. Shields, D.J.; Šolarb, S.V.; Martin, W.E. The role of values and objectives in communicating indicators of sustainability. Ecol. Indic. 2002, 2, 149-160.

6. Mitchell, G.; May, A.; McDonald, A. PICABUE: A methodological framework for the development of indicators of sustainable development. Int. J. Sustain. Dev. World Ecol. 1995, 2, 104-123.

7. Holling, C.S. Adaptative Environmental Assessment and Management; Wilrey: London, UK, 1978.

8. Marimon, F.; Alonso-Almeida, M.M.; Rodriguez, M.P.; Cortez, C.A. The worldwide diffusion of the global reporting initiative: What is the point? J. Clean. Prod. 2012, 33, 132-144.

9. Perez-Batres, L.A.; Miller, V.V.; Pisani, M.J. CSR, sustainability and the meaning of global reporting for Latin American corporations. J. Bus. Ethics 2010, 91, 193-209.

10. Brown, H.S.; de Jong, M.; Levy, D.L. Building institutions based on information disclosure: Lessons from GRI's sustainability reporting. J. Clean. Prod. 2009, 17, 571-580.

11. Global Reporting Initiative. What is GIR. Available online: https://www.globalreporting.org/ information/about-gri/what-is-GRI/Pages/default.aspx (accessed on 20 December 2014).

12. Global Reporting Initiative. Available online: http://www.globalreporting.org (accessed on 12 November 2014).

13. METADATA - Statistical Classification of Economic Activities in the European Community, Rev. 2 (2008). Available online: http://ec.europa.eu/eurostat/ramon/nomenclatures/index.cfm?Target Url=LST_NOM_DTL\&StrNom=NACE_REV2\&StrLanguageCode=EN (accessed on 12 November 2014).

14. Vicente-Villardon, J.L.; Galindo-Villardon, M.P.; Blazquez-Zaballos, A. Logistic Biplots. In Multiple Correspondence Analysis and Related Methods; Greenacre, M., Blasius, J., Eds.; Statistics in Social and Behavioral Sciences Series: Boca Raton, FL, USA, 2006; pp. 503-521.

15. Demey, J.R.; Vicente-Villardón, J.L.; Galindo, M.P.; Zambrano, A.Y. Identifying molecular markers associated with classifications of genotypes by external logistic biplot. Bioinformatics 2008, 24, 28-32.

16. Alazzani, A.; Wan-Hussin, W.N. Global reporting initiative's environmental reporting: A study of oil and gas companies. Ecol. Indic. 2013, 32, 19-24.

17. MultiBiplot-Multivariate Analysis using Biplots. Available online: http://biplot.usal.es/ ClassicalBiplot/index.html (accessed on 12 November 2014). 
18. Gower, J. A general coefficient of similarity and some of its properties. Biometric 1971, 27, 857-874.

19. Galindo, P.V.; Vaz, T.N.; Nijkamp, P. Institutional capacity to dynamically innovate: An application to the Portuguese case. Technol. Forecast. Soc. Change 2010, 78, 3-12.

20. Vaz, E.; Noronha, T.; Vicente-Galindo, P.; Nijkamp, P. Modelling innovation support systems for regional development-Analysis of cluster structures in innovation in Portugal. Entrepren. Reg. Dev. 2014, 26, 23-46.

21. Gallego-Álvarez, I.; Vicente-Villardón, J.L. Analysis of environmental indicators in international companies by applying the logistic biplot. Ecol. Indic. 2012, 23, 250-261.

22. Global Reporting Initiative. Sustainable Reporting Guidelines. 2006. Available online: http://www.globalreporting.org (accessed on 4 November 2014).

23. Molden B.; Janoušková, S.; Hák, T. How to understand and measure environmental sustainability: Indicators and targets. Ecol. Indic. 2012, 17, 4-13.

(C) 2015 by the authors; licensee MDPI, Basel, Switzerland. This article is an open access article distributed under the terms and conditions of the Creative Commons Attribution license (http://creativecommons.org/licenses/by/4.0/). 